\title{
No mar brasileiro agitado pela COVID-19, não estamos todos no mesmo barco
}

\author{
In the Brazilian sea agitated by COVID-19, we're not all in the same boat \\ En el mar brasileño agitado por la COVID-19, no todos estamos \\ en el mismo barco
}

Luís Paulo SOUZA e SOUZA ${ }^{(1)}$

Antônia Gonçalves de SOUZA ${ }^{(2)}$

Recebido: 6 jun 2020

Revisado: 1 jul 2020

Aceito: 9 jul 2020

Autor de

correspondência:

Luís Paulo Souza e Souza

luis.pauloss@hotmail.com

Conflito de interesses:

Os autores declaram não haver nenhum interesse profissional ou pessoal que possa gerar conflito de interesses em relação a este manuscrito.

\begin{abstract}
Resumo
A pandemia da COVID-19 é a pior crise sanitária do século. Inicialmente, parecia consenso que o SARS-CoV-2 não escolhia classe, raça ou região, espalhando-se rapidamente de um corpo para o outro, contudo, as maneiras como os corpos estão dispostos no mundo variam a partir de marcadores sociais de desigualdades. No Brasil, a doença colocou em destaques importantes iniquidades já existentes, que seguiram seu curso com a pandemia (com alguns agravamentos); e, neste artigo, discutem-se algumas delas. Avaliando as medidas para contenção do vírus, ao mesmo tempo que visam proteger um determinado segmento da sociedade, deixam outros completamente desprotegidos, destacando-se os que não têm acesso à internet; desempregados; trabalhadores informais; os pretos e pardos; os de menor renda e escolaridade; os que residem no Norte e Nordeste. A pandemia no Brasil tem classe social, raça, cor e região; e, nesse mar agitado por ela, algumas pessoas estão em navios com serviços all inclusive, outras em lanchas, uma parte em barcos a remo, e outros tantos atravessando a nado. O país precisa pensar sobre qual projeto usar para enfrentamento da pandemia: seria um projeto que olha para as vulnerabilidades ou será o que segue em curso - deixando morrer uma parte da população, principalmente, a mais pobre? Além dos desafios da doença, o país ainda vivencia o impasse de ter um comandante do navio despreparado, cuja postura é claramente anticientífica e negacionista, deixando o navio à deriva. Discutir os princípios do Sistema Único de Saúde - SUS se faz importante, para garantir que sejam legitimados neste momento. A adoção de políticas públicas para superação das desigualdades é urgente, com forte participação social, possibilitando que esses grupos estejam mais fortalecidos para encararem desafios futuros; dando, no mínimo, condições mais dignas para atravessarem outros mares ou tempestades - caso sobrevivam ao mar revolto da COVID19.
\end{abstract}

Descritores: Infecções por Coronavirus; SARS-CoV-2; Determinantes Sociais da Saúde; Iniquidade Social; Saúde Pública. 


\begin{abstract}
The COVID-19 pandemic is the worst health crisis of the century. Initially, there seemed consensus that the SARS-CoV-2 did not choose class, race or region, spreading rapidly from one body to another, however, the ways in which bodies are disposed in the world vary from social markers of inequalities. In Brazil, the disease has highlighted important existing inequities, which followed its course with the pandemic (with some aggravations); and, in this article, some of them are discussed. When assessing measures to contain the virus, some aim to protect a particular segment of society, but leave others completely unprotected, highlighting those who do not have access to the Internet; the unemployed; informal workers; blacks and browns; those with lower income and schooling; and those living in regions North and Northeast. The pandemic in Brazil has social class, race, color and region; and in this "sea agitated by it", some people are on ships with all-inclusive, others in speedboats, a part in rowboats, and so many others going through the swim. The country needs to think about which project to use to cope with the pandemic: would it be a project that looks at vulnerabilities or will it be what is ongoing - which lets a part of the population die, especially the poorest? In addition to the challenges of the disease, the country still experiences the impasse of having an unprepared ship commander, whose stance is clearly unscientific and negationist, leaving the ship adrift. It's important to discuss the principles of the Sistema Único de Saúde- SUS, to ensure that they are legitimized at this moment. The adoption of public policies to overcome inequalities is urgent, with strong social participation, enabling these groups to be strengthened to face future challenges; giving, at least, more dignified conditions to cross other "seas or storms". All lives matter, however, it is sad to recognize that not all were built to matter. That is why strengthening is paramount: all lives matter, because living is everyone's right.
\end{abstract}

Keywords: Coronavirus Infections; SARS-CoV-2; Social Determinants of Health; Social Inequity; Public Health.

\title{
Resumen
}

La pandemia COVID-19 es la peor crisis sanitaria del siglo. Inicialmente, parecía haber consenso que el SARS-CoV-2 no elegía clase, raza o región, extendiéndose rápidamente de un cuerpo a otro, pero, las formas en que los cuerpos se eliminan en el mundo varían de marcadores sociales de desigualdades. En Brasil, esta enfermedad ha puesto de relieve importantes desigualdades existentes, que siguieron su curso con la pandemia (con algunos agravantes); $y$, en este artículo, algunos de ellas son discutidas. Al evaluar las medidas para contener el virus, mientras que algunas protegen a un segmento de la sociedad, pero dejan otro completamente desprotegido, especialmente aquellos que no tienen acceso a internet; los desempleados; trabajadores informales; negros y marrones; aquellos con menores ingresos y escolaridad; y los que viven en regiones Norte y Noreste. La pandemia en Brasil tiene clase social, raza, color y región; y en este mar agitado por ella, algunas personas están en naves con servicios all inclusive, otros en lanchas rápidas, una parte en botes de remos, y tantos otros nadando en el brazo. El país tiene que pensar en qué proyecto utilizar contra la pandemia: ¿sería un proyecto que examina las vulnerabilidades o será lo que está en curso - que permite que una parte de la población muera, especialmente los más pobres? Además de los desafíos da enfermedad, el país experimenta la dificultad de tener un comandante de nave no preparado, cuya postura es claramente poco científica y negacionista, dejando la nave a la deriva. Discutir los principios del Sistema Único de Saúde - SUS es importante, para asegurar que estén legitimados en este momento. Adopción de políticas públicas para superar las desigualdades es urgente, con una fuerte participación social, permitiendo que estos grupos se fortalezcan para experimentar los desafíos futuros; dando, al menos, condiciones más dignas para cruzar otros "mares o tormentas". Todas las vidas importan, pero, es triste reconocer que no todas fueron construidas para le importar. El fortalecimiento es primordial: todas las vidas importan, porque vivir es derecho de todos.

Palabras-claves: Infecciones por Coronavirus; SARS-CoV-2; Determinantes Sociales de la Salud; Inequidad Social; Salud Pública. 


\section{Ajustando os motores, os remos [e os braços] ...}

O ano 2020 iniciou marcado pela pandemia da COVID-19, maior crise sanitária do século. Mundialmente, até o dia 08 de julho, foram registrados 11.669 .259 casos e 539.906 mortes.

Em primeira análise, parecia consenso que o novo coronavírus (SARS-CoV-2) não escolhia classe, raça ou região, espalhando-se rapidamente de um corpo para o outro. Contudo, as maneiras como os corpos e as superfícies estão dispostas no mundo variam de acordo com marcadores sociais de desigualdades.

Estudos apontam que, apesar de os patógenos não escolherem classe social, fatores referentes às condições de vida das pessoas são determinantes para a taxa de contaminação e para a velocidade de propagação de algumas doenças. ${ }^{2-4} \mathrm{Com}$ a chegada do SARS-CoV-2 no Brasil, é impossível não debater a infecção como uma questão social, que atinge grupos distintos de maneiras diferentes. A COVID-19 colocou em destaques importantes iniquidades já existentes no país, as quais seguiram seu curso com a pandemia (com alguns agravamentos). Assim, neste texto, pretende-se discutir sobre algumas destas iniquidades nos contextos brasileiro e pandêmico.

\section{Mar adentro ...}

O primeiro caso brasileiro de COVID-19 foi confirmado no dia 25 de fevereiro de 2020, em São Paulo. ${ }^{5}$ Em pouco tempo, outros estados também fizeram registros, tendo surgindo, inicialmente, em pessoas das classes média e alta que viajaram para o exterior, dando uma primeira impressão de que era doença de rico. Ainda no final de fevereiro, os brasileiros foram bombardeados pelas mídias sobre as formas de higienização das mãos com água e sabão; uso do álcool em gel; e uso das máscaras faciais. As pessoas foram instruídas a não tocarem as superfícies, cumprimentarem por acenos ou toques de pés, e a realinharem a distância física nos afetos da vida.

Como o avanço da doença, passando para transmissão comunitária, as autoridades brasileiras adotaram novas medidas: suspender aulas presenciais, transferindo para o ensino a distância; restringir o tráfego de pessoas dentro e entre as cidades e os estados; estimular a população a trabalhar em home office e a não sair de casa, enfatizando o distanciamento social. Apesar de tais recomendações serem embasadas cientificamente, ${ }^{6}$ é difícil não pensar que elas elucidam tristes desigualdades sociais no Brasil. O país já é considerado um dos que apresenta mais casos da doença: até o dia 08 de julho, confirmaram-se 1.713 .160 casos e 67.964 mortes. ${ }^{5}$ Contudo, o classismo e o regionalismo marcam estes casos e óbitos. 
Com a suspensão das aulas presenciais, instituindo tecnologias de informação e comunicação (TIC) para tentar salvar o semestre, como ficam aqueles que não têm acesso à internet - nem mesmo aquela de conexão lenta? Segundo a pesquisa TIC Domicílios, ${ }^{7}$ em 2018, 70\% dos domicílios urbanos tinham acesso à internet, enquanto apenas 44\% dos rurais tinham este serviço. Somente $19 \%$ das casas tinham computador de mesa e $27 \%$ apresentavam computador portátil. Entre os das classes A e B, 96,5\% tinham sinal de internet; e entre os das classes $D$ e $E, 59 \%$ não conseguiam navegar na rede. Ademais, $O$ acesso era maior entre as pessoas com maior escolaridade. Outro ponto é a velocidade da conexão, pois em grande parte das casas, não se tem acesso à internet de banda larga, sem contar que a relação preço-serviço é desproporcional entre as regiões. ${ }^{7}$ Como exemplo, citam-se os estados do Amazonas e Roraima, que apresentam muitos municípios sem internet de qualidade, além das cidades que conseguem ofertar o sinal a um valor "absurdamente exorbitante" (com uso intencional da redundância).

Com a recomendação de trabalhar em casa, como ficam os desacobertados pela formalidade do trabalho? No primeiro trimestre de 2020, 12,9 milhões de pessoas estavam desempregadas. ${ }^{8}$ Além disso, 38 milhões de brasileiros trabalhavam informalmente, ou seja, trabalhadores sem carteira assinada ou empregadores sem Cadastro Nacional da Pessoa Jurídica - CNPJ, ${ }^{8}$ neste bojo estão parte das empregadas domésticas, os feirantes, o vendedor de balas no sinal, os entregadores de encomendas ou a senhora que vendia suas quentinhas na praia. O Instituto de Pesquisa Econômica e Aplicada - IPEA ${ }^{9}$ apontou que, na primeira semana de junho de 2020, apenas 22,7\% dos empregos no Brasil podem ser realizados inteiramente em casa, sendo que há variações significativas entre os estados e os tipos de atividades ocupacionais. ${ }^{9}$ Desta forma, percebe-se que são muitos os que não terão o luxo (ou privilégio?) do home office e terão de continuar trabalhando fora de casa e se expondo, além de boa parte deles ainda serem os que terão de encarar as enormes filas das agências bancárias para receberem o auxílio emergencial do governo. Como resposta à crise econômica decorrente da pandemia, o Governo do Brasil sancionou uma lei que instituiu o auxílio emergencial, destinando $\mathrm{R} \$ 600,00$ a trabalhadores informais, microempreendedores individuais, contribuintes individuais da Previdência Social e desempregados. Contudo, o governo optou por um modelo centralizado e totalmente digitalizado, o que gerou gargalos na implementação. Além disso, houve erros em registros administrativos sobre os dados pessoais, vínculo empregatício e até indicação equivocada de óbito, fazendo com que pessoas que tivessem o direito ao auxílio não conseguissem recebê-lo, e com que muitas outras comparecessem presencialmente às agências bancárias, gerando longas filas e aglomerações. $^{10}$

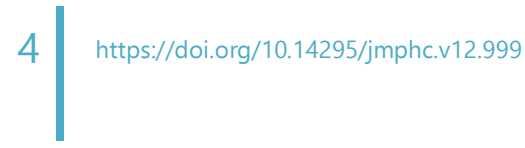


Com a recomendação de lavar as mãos, como ficam aqueles que não têm acesso à água? Para 35 milhões de brasileiros, a água para lavar, cozinhar e cuidar dos seus familiares não é uma realidade. ${ }^{11} \mathrm{E}$ quando se destacam os territórios como as periferias ou favelas, as disparidades aumentam. ${ }^{12}$ Enquanto uma parte da sociedade passa o sabonete nas palmas das mãos, entre os dedos e no punho, várias vezes ao dia, as consequências extremadas de um país distópico pandêmico seguem seu curso, demarcando quase um apartheid sanitário.

Recomendado o distanciamento social, como ficam aquelas moradias com alta densidade domiciliar? Cerca de 13 milhões de brasileiros vivem em casas que abrigam, em média, três ou mais pessoas por quarto. ${ }^{12}$ Nesse sentido, as análises de risco e de avaliação do grau de vulnerabilidade socioespacial devem orientar diferentes estratégias nas diversas escalas territoriais e esferas governamentais. ${ }^{13}$

Com as orientações preventivas divulgadas pelos meios de comunicação, como ficam as populações com especificidades relacionadas à escolaridade e à renda? Segundo estudo recente da Pontifícia Universidade Católica do Rio de Janeiro - PUC-Rio, ${ }^{14}$ os sem escolaridade têm taxas três vezes superiores $(71,3 \%)$ aos que têm nível superior $(22,5 \%)$. Os autores destacam que as desigualdades de renda e acesso a serviços básicos sanitários confirmam o impacto da doença nas classes brasileiras. ${ }^{14}$

Frente aos planos de contingência para a população brasileira, como ficam as pessoas segundo as regiões de moradia? Mesmo a Região Sudeste apresentando maior número absoluto de casos até o dia 08 de julho (590.266), ${ }^{5}$ quando se analisa a Taxa de Incidência por 100 mil habitantes, a realidade choca: a Região Norte lidera com 1.640,2; seguida pelo Nordeste (1.017,4); Centro-Oeste $(809,2)$, Sudeste $(667,9)$; e Sul $(360,6)$. Analisando a Taxa de Mortalidade por 100 mil habitantes, a Região Norte apresenta-se tristemente desfavorável, com uma taxa de 55,4; seguida da Nordeste $(38,6)$; Sudeste $(35,1)$; CentroOeste $(15,6)$; e Sul $(7,2){ }^{5}$ Cabe destacar que a Região Norte apresenta outro fator que a coloca em situação mais desigual, por apresentar dados ligeiramente piores em relação ao abastecimento de água e esgotamento sanitário adequados. ${ }^{15}$

Levando em consideração as recomendações e cuidados adotados pelos gestores (nas três esferas), como se comporta a doença em relação à raça/cor das pessoas? Segundo boletim do Ministério da Saúde divulgado no dia 13 de junho, 40\% dos óbitos foi de pessoas pardas e pretas; considerando que o órgão classificou as pessoas em brancas, pretas, amarelas, pardas, indígenas, sem informação e dado ignorado. ${ }^{16}$ Cabe destacar que o Ministério da Saúde e as Secretarias de Saúde dos Estados só passaram a incluir informações raça/cor dos pacientes nos boletins epidemiológicos no dia 11 de abril - quase dois meses 
após o primeiro caso no país. Isso reforça o descaso com estas populações, imprimindo a ideia de que o SARS-CoV-2 é "democrático", mas não é! Dados recentes de uma pesquisa conduzida pela Universidade de Cambridge em parceira com a Universidade Federal do Espírito Santo - UFES reforçaram que pessoas pardas e pretas têm mais chances de morrer pela COVID-19 no Brasil, principalmente nas Regiões Norte e Nordeste. ${ }^{17}$ O estudo apontou, ainda, que as pessoas que vivem nas outras Regiões apresentam menos riscos em relação à infecção, porém, a população negra que vive em São Paulo, por exemplo, apresentava 62\% mais chance de morrer pela COVID-19 do que a população branca. Os autores enfatizam que os resultados exigem esforços urgentes por parte das autoridades brasileiras para considerarem nas propostas de enfrentamento da doença alternativas que projetam os pardos e pretos, bem como a população dos estados mais pobres, do maior risco de morte pela COVID-19. ${ }^{17}$

No estudo feito pela PUC-Rio, os autores encontraram que, além da raça/cor, fatores como instrução também estão ligados à letalidade da COVID-19: os negros sem escolaridade apresentaram até 3,8 vezes mais chances de morrer pelo novo coronavírus. As pessoas pretas e pardas tinham risco de morte $37 \%$ maior que as brancas com a mesma escolaridade. ${ }^{14}$ Estes dados precisam ser fortemente considerados pelo Governo, pois já se sabe que esta população é menos atendida pelas redes de proteção social, apresenta-se nas classes sociais mais inferiores, com menos possibilidades de trabalharem remotamente.

Surge, pois, a necessidade de a população reconhecer e lutar pelo fim das iniquidades, saindo da inércia que paira diante das faces, organizando lutas coletivas para marcarem quem são, como estão e como não querem mais ser tratadas. Reconhece-se que os últimos meses têm sido difíceis, frente a tantos absurdos e golpeamentos vividos, fazendo com as pessoas se apresentem paralisadas, vendo as coisas ruins acontecerem como se fossem comuns, contudo, romper essa forma fantasmagórica de poder do Estado é interromper a corrente militarista e autoritária do governo. ${ }^{18}$

Assim, em um primeiro momento, observa-se que as medidas de distanciamento, trabalho home office, informações de prevenção do contágio, alternativas de auxílio social, e estratégias dos planos de contingência, até aqui discutidas, ao mesmo tempo em que visam proteger um determinado segmento da sociedade, deixam outros completamente desprotegidos. Infelizmente, as pessoas não atingidas são as da base da pirâmide social. É evidente que muitos destes profissionais citados continuarão trabalhando, que as pessoas continuarão muito próximas umas das outras, e que tantas outras não lavarão suas mãos. $E$ mesmo que fiquem doentes, provavelmente, continuarão nas mesmas situações, uma vez que no mercado informal não há nenhuma proteção e não tem sido demonstrado interesse 
do Estado em buscar opções para melhor distribuição territorial e acesso ao saneamento básico, e nem tem sido apresentados planos que considerem as especificidades raciais e regionais.

Esta pandemia tem classe social, raça, cor e região; e, nesse mar agitado por ela, algumas pessoas estão em navios com serviços all inclusive, outras em lanchas e iates, uma parte em barcos a remo, e outros tantos atravessando a nado. A vulnerabilidade é profundamente desigual entre as pessoas; e em cada barco, há um modo de produzir vida e os consequentes efeitos dessa produção na mente, na alma, no corpo, no território, na cidade. Por isso, importa o lugar e as formas como as pessoas vivem, moram e trabalham no processo saúde-adoecimento-cuidado.

O momento é crucial para repensarmos a vida em sociedade e de como o conceito de coletividade tem sido incorporado em nosso meio. O que nos permite ter alguma esperança é que, com o maior sistema de acesso universal à saúde do mundo, o Sistema Único de Saúde - SUS, não partimos do zero no combate à COVID-19. E, talvez, seja este um ponto que possa nos igualar neste mar aberto. Por isso, revogar a Emenda Constitucional 95 (EC 95) é algo urgente, pois bilhões de reais não foram e não serão investidos no SUS que, agora, tem sido tão demandado. Conhecida como política do teto dos gastos, a EC 95 foi adotada em dezembro de 2016 e prevê que, durante 20 anos, as despesas primárias do orçamento público ficarão limitadas à variação inflacionária. Ou seja, mesmo que o Estado aumente a arrecadação federal, não haverá mais investimentos nas áreas sociais, incluindo o setor saúde, desconsiderando o impacto do crescimento populacional, a transição demográfica, e os custos associados à mudança do perfil assistencial determinado pela prevalência de agravos não transmissíveis e de outras doenças emergentes e enfermidades infecciosas. ${ }^{19}$

Reconhecendo que, neste texto, não foram listados todos os grupos que têm seus corpos e almas suscetíveis, vulneráveis e vulnerabilizados no Brasil frente à COVID-19, é preciso enfatizar que a característica democrática do novo coronavírus é uma falácia. Como destacam Kenneth Camargo e Jane Russo, ${ }^{20}$ em editorial na Revista Physis. Lembremos que esse vírus tem uma vida social, interage com um mundo de diferenças, impacta países, faixas etárias, grupos de risco, classes sociais, gênero e raça de modos distintos. ${ }^{20: 4}$

\section{Terra à vista?}

Ao encerrar este texto, citamos o trecho de uma música de um compositor chamado Tiago Arrais ${ }^{21}$, que mesmo não tendo sido escrito no atual contexto, retrata como nossos corpos podem estar dispostos em barcos diferentes. 
A vida é um mar, a experiência humana uma embarcação, nós os condutores. No mar, milhões de barcos; uns estão isolados de todos, outros estão em conflito com outros. Uns estão parados observando o movimento de outros barcos, outros afundam sem mesmo se aperceberem disto. Uns remam com força em diversas direções, outros se deixam levar pelo vento enquanto assobiam melodias de canções familiares. E a pergunta? Ah sim! A pergunta que reverbera nas paredes do coração de cada ser humano desde o primeiro pôr do sol, desde que o primeiro barco deixou o primeiro rastro na areia em direção ao incerto, em direção a territórios não mapeados é: Existe algo além do que os nossos olhos hoje podem ver? Existe um lar do outro lado desse mar? Existe mais?". ${ }^{21: \text { tela } 1}$

O "Existe mais?" nos faz refletir no que ainda estar por vir, sem deixar de pensarmos sobre qual projeto do agora precisamos usar para enfrentar a pandemia: seria um projeto que olha para as vulnerabilidades ou será o que segue em curso - que tem deixado morrer uma parte da população, principalmente, a mais pobre?

Estamos diante da maior crise do século; o tempo é nosso maior aliado e a ciência é a única que pode responder a esse caos. Todavia, além dos desafios da pandemia, o país vivencia o impasse de ter um comandante do navio totalmente despreparado para guiar a embarcação, cuja postura é claramente anticientífica e negacionista. "E daí?", disse o comandante. E daí, que a conta dos naufrágios só aumenta: em vidas perdidas, em gastos econômicos e em reputação internacional. O navio está à deriva.

Faz-se necessário explicitar e medir diferenças como um ponto de partida para a formulação de políticas públicas justas. Debater sobre os princípios da universalidade, da integralidade, da equidade, da participação social, do acesso, da regionalização, entre outros, é outro ponto essencial neste momento, reconhecendo que, para legitimá-los, é preciso comportar o direito às diferenças e a noção de determinação social das doenças, tendo em vista que não se trata mais de um padrão homogêneo, mas de um padrão equânime.

Medidas de cuidados aos mais vulneráveis não devem ser pauta apenas neste contexto pandêmico. Deve-se garantir a efetivação de políticas públicas e a participação da comunidade para superação das desigualdades, possibilitando que esses grupos estejam mais fortalecidos para encararem desafios futuros; dando, no mínimo, condições mais dignas para atravessarem outros mares ou tempestades - caso sobrevivam ao mar revolto da COVID-19.

\section{Referências}

1. World Health Organization. Coronavirus disease (COVID-2019) situation reports: Situation report - 170. Genebra: WHO; 2020. 
2. Leal AF, Lui L. Instituições participativas e seus efeitos nas políticas públicas: estudo do Comitê de Mortalidade por Aids de Porto Alegre. Saude Soc. 2018;27:94-105. https://doi.org/10.1590/s0104-12902018170425.

3. Lesser J, Kitron U. A geografia social do Zika no Brasil. Estud Av. 2016;30(88):167-75. https://doi.org/10.1590/s0103-40142016.30880012.

4. Johansen IC, Carmo RL, Alves LC. Desigualdade social intraurbana: implicações sobre a epidemia de dengue em Campinas, SP, em 2014. Cad Metrop. 2016;18(36):421-40. https://doi.org/10.1590/2236-9996.2016-3606.

5. Ministério da Saúde (BR). COVID19: painel coronavírus Brasil. Brasília, DF: MS; 2020 [citado 7 jun. 2020]. Disponível em: http://covid.saude.gov.br.

6. Ferguson NM, Laydon D, Nedjati-Gilani G, Imai N, Kylie A, Marc Baguelin, et al. Impact of non-pharmaceutical interventions (NPIs) to reduce COVID-19 mortality and healthcare demand. London: Imperial College London; 2020. http://doi.org/10.25561/77482.

7. Comitê Gestor da Internet no Brasil. Pesquisa sobre o uso das tecnologias de informação e comunicação nos domicílios brasileiros: TIC domicílios 2018. São Paulo: CGI.br; 2019.

8. Instituto Brasileiro de Geografia e Estatística. Desemprego. Rio de Janeiro: IBGE; 2020 [citado 5 jun. 2020]. Disponível em: https://www.ibge.gov.br/explica/desemprego.php

9. Góes GS, Martins FS, Nascimento JAS. Potencial de teletrabalho na pandemia: um retrato no Brasil e no mundo. Carta Conjuntura. 2020;47:1-10.

10. Malin AMB, Lopes B, Moreira D, Gomes J, Machado L, QuintsIr M, et al. Covid-19: acesso à informação pública. Rio de Janeiro: UFRJ-IBICT; 2020 [citado 7 jul. 2020]. Disponível em: http://obgi.org/wp-content/uploads/2020/06/comunicado_03_VF.pdf

11. Nascimento DM. Lavar as mãos contra o coronavírus: mas, e a água?. APS Rev. 2020;2(1):66-9. http://doi.org/10.14295/aps.v2i1.61.

12. COVID-19 in Brazil: "so what?". Lancet. 2020;395(10235):1461. http://doi.org/10.1016/S0140-6736(20)31095-3.

13. Costa MA, Lui L, Santos RM, Curi RLC, Albuquerque CG, Tavares SR, et al. Apontamentos sobre a dimensão territorial da pandemia da Covid-19 e os fatores que contribuem para aumentar a vulnerabilidade socioespacial nas unidades de desenvolvimento humano de áreas metropolitanas brasileiras. Brasília, DF: IPEA; 2020. 
14. Diferenças sociais: pretos e pardos morrem mais de COVID-19 do que brancos, segundo NT11 do NOIS. Rio de Janeiro: PUC-Rio; 2020 [citado 5 jun. 2020]. Disponível em: http://www.ctc.puc-rio.br/diferencas-sociais-confirmam-que-pretos-e-pardos-morremmais-de-covid-19-do-que-brancos-segundo-nt11-do-nois/

15. Ministério de Desenvolvimento Regional (BR). Diagnóstico dos serviços de água e esgotos. Brasília, DF: Sistema Nacional de Informações sobre Saneamento; 2018 [citado 5 jun. 2020]. Disponível em: http://www.snis.gov.br/diagnostico-anual-agua-eesgotos/diagnostico-dos-servicos-de-agua-e-esgotos-2018

16. Especial: COVID-19. Bol Epidemiol. 2020;(18):1-42.

17. Baqui PO, Bica I, Marra V, Ercole A, Schaar MVD. Ethnic and regional variation in hospital mortality from COVID-19 in Brazil: a cross-sectional observational study. Lancet. 2020;8(8):E1018-26. doi: https://doi.org/10.1016/S2214-109X(20)30285-0.

18. Coletivo Centelha. Ruptura. São Paulo: n-1 edições; 2019.

19. Menezes APR, Moretti B, Reis AAC. O futuro do SUS: impactos das reformas neoliberais na saúde pública - austeridade versus universalidade. Saude Debate. 2020;43(spe5):5870. http://doi.org/10.1590/0103-11042019s505.

20. Camargo Jr KR, Russo J. All things... Physis. 2020;30(2):e300200. https://doi.org/10.1590/S0103-73312020300200.

21. Arrais T. Mais (Os Arrais) [vídeo]. 17 jan. 2016 [citado 5 jun. 2020]. Disponível em: http://www.youtube.com/watch?v=JBWc_6Br10.

\section{Minicurrículo}

Luís Paulo Souza e Souza | ORCiD: 0000-0002-9801-4157

Doutor em Saúde Pública pela Universidade Federal de Minas Gerais - UFMG. Pós-Doutorado em Educação pela Universidade do Estado do Pará - UEPA. Pós-Doutorado em Desenvolvimento Regional pela Universidade de Santa Cruz do Sul - UNISC. Professor Adjunto do Curso de Graduação em Medicina do Instituto de Saúde e Biotecnologia - ISB da Universidade Federal do Amazonas - UFAM, Brasil.

Antônia Gonçalves de Souza | ORCiD: 0000-0003-3117-0291

Especialista em Psicologia Social pela Faculdade Mantenense dos Vales Gerais - INTERVALE. Pós-Graduanda em Direitos Humanos pela Universidade Federal dos Vales do Jequitinhonha e Mucuri - UFVJM. Pesquisadora do Instituto de Saúde e Biotecnologia - ISB da Universidade Federal do Amazonas - UFAM, Brasil 